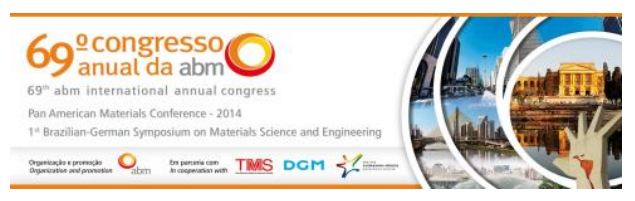

Tema: Produtos metálicos não-ferrosos

\title{
OTIMIZAÇÃO DO PROCESSO DE FRESAMENTO E ANÁLISE DE TENSÕES RESIDUAIS NA LIGA TI6AI4V*
}

\author{
Osmar Roberto Bagnato ${ }^{1}$ \\ Bruno de Cristo 2 \\ Miqueias Vieira ${ }^{3}$ \\ Matheus Vellon Alves ${ }^{4}$ \\ Roosevelt Droppa Júnior ${ }^{5}$
}

\section{Resumo}

Este trabalho apresenta um estudo do desgaste de insertos e tensões residuais em diferentes estratégias de entrada de ferramenta no fresamento da liga Ti-6Al-4V. Esta liga possui propriedades mecânicas que a torna ideal para aplicações onde é necessária uma ótima relação resistência-peso. $O$ objetivo é reduzir o desgaste dos insertos no processo de fresamento e analisar as tensões residuais na usinagem da liga Ti-6Al-4V. A integridade superficial do material após a usinagem deve ser conhecida já que esta liga é utilizada em aplicações criticas. Quatro estratégias de entrada foram estudadas, sendo que no faceamento foi utilizada a entrada por rolagem e a frontal reta e no fresamento de cavidade foi utilizado mergulho reto e em rampa. Em todos os ensaios foram utilizados os mesmos parâmetros de usinagem. As tensões residuais foram medidas por difração de raios-X (Luz Sincrotron), pelo método $\sin ^{2} \psi$, utilizando um difratômetro de raios-X instalado no LNLS. No faceamento a estratégia por rolagem mostrou uma importante redução do desgaste e uma pequena redução da tensão residual quando comparada com a estratégia frontal reta. No fresamento de cavidades a estratégia de mergulho reto mostrou um inesperado aumento do desgaste e uma significativa redução da tensão residual quando comparada com o mergulho em rampa. Todas as tensões residuais encontradas foram compressivas. As tensões residuais encontradas em todos os experimentos se mostraram favoráveis a aplicações sujeitas à fadiga.

Palavras-chave: Usinagem; Titânio; Desgaste; Tensão residual;

\section{OPTIMIZATION OF FACE AND DIVE MILLING PROCESSES USING INTERCHANGEABLE INSERTS ON Ti6Al4V}

\section{Abstract}

This work presents a study of the inserts wear and residual stresses at different tool entry strategies in milling of Ti6Al4V alloy. This alloy has mechanical properties that make it ideal for applications where great strength to weight ratio is needed, like in aerospace industry. However, there is still a great difficulty in manufacturing this alloy, which increases production costs. In order for the application of this alloy to be competitive it is necessary to have a strong optimization of the machining process. The aim of this work is to reduce inserts wear in titanium milling process and analyze the residual stresses in machining of Ti6Al4V alloy. The surface integrity of the material after machining should be analyzed because this alloy is used in critical applications. Previous work proved that it is possible to obtain better results in terms of the amount of material removed and optimizing machining times entry strategies in face milling and diving in pocket milling in different materials and it is known that the machining process influences the residual stresses of the processed surface. Four tool entry strategies were studied. On face milling, the straight and roll-in entry was used and on pocket milling straight plunge and ramp dive. All experiments considered the same machining parameters (feed, cutting speed and depth of cut). The surface residual stresses were measured by X-ray diffraction (Synchrotron Radiation) by $\sin ^{2} \psi$, using an X-ray diffractometer installed at LNLS. On face milling the roll-in strategy showed a significant reduction in flank wear and a small reduction in residual stress if compared with the straight entry strategy. Pocket milling straight plunge strategy showed an unexpected increase in flank wear and a significant reduction of residual stress when compared with the ramp strategy. All superficial residual stresses found in the experiments were compressive. It is concluded that the roll-in strategy provides insert consumption reduction, and straight plunge strategy showed no improvement regarding of wear. Residual stresses found in all experiments were beneficial to the application when subjected to fatigue.

Keywords: Machining; Milling; Wear; Titanium; Residual Stress; Synchrotron.

1 Engenheiro de Materiais, Doutor em Engenharia Mecânica, Líder do Grupo de Materiais, Laboratório Nacional de Luz Síncrotron (LNLS), CNPEM, Campinas, SP, Brasil.

2 Engenheiro Mecânico, Supervisor de manutenção, petroquímica BRASKEM, Paulínia, SP, Brasil.

3 Eng. Mecânico, Projetista CAD/CAM Sênior, Eng. Processos, Hernandes Fim \& Cia Ltda. (Finetornos), Campinas, SP, Brasil.

4 Eng. Mecânico, Assistente de Engenharia, Engenharia de Aplicação, Gardner Denver Nash Brasil, Campinas, SP, Brasil.

5 Doutor em Física, Professor adjunto, Centro de Ciências Naturais e Humanas (CCNH), Universidade Federal do ABC, Santo André, SP, Brasil.

\footnotetext{
* Contribuição técnica ao 69 Congresso Anual da ABM - Internacional e ao 14ํ ENEMET - Encontro Nacional de Estudantes de Engenharia Metalúrgica, de Materiais e de Minas, 21 a 25 de julho de 2014, São Paulo, SP, Brasil.
} 


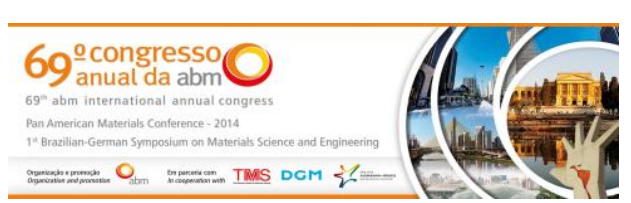

\section{INTRODUÇÃO}

As ligas de titânio possuem propriedades mecânicas que as tornam ideais para aplicação em diversas indústrias, entre elas a aeronáutica [1]. A relação resistênciapeso aliada à resistência à corrosão a colocam à frente das várias ligas de aço e de alumínio existentes no mercado. Porém ainda há grande dificuldade na fabricação de produtos com esse material, tanto pela baixa usinabilidade como pelo alto ponto de fusão, que acabam aumentando o custo de produção e em diversos casos tornando-se inviável em vista da facilidade de obtenção de ligas de aço ou de alumínio de alta resistência e boa usinabilidade. A baixa produtividade se deve à utilização de reduzidas velocidades de corte quando comparadas às dos aços, uma vez que a temperatura na região do corte é extremamente elevada devido à baixa condutividade térmica do material [1]. Outros fatores determinantes são a afinidade química do titânio com os diversos materiais que revestem as ferramentas de corte, causando o desgaste por difusão, e seu baixo módulo de elasticidade que provoca instabilidade e vibrações durante a usinagem. É possível obter melhores resultados em termos de quantidade de material removido e tempos de usinagem otimizando as estratégias de entrada no fresamento frontal [2] e de mergulho no fresamento de cavidades [3], além de se aplicar ferramentas com ângulo de posição que atenue as vibrações [1]. As tensões residuais resultantes destas estratégias podem ser mensuradas através da difração de Raios- $X$, permitindo avaliar o quanto as variáveis controladas influenciam na resistência à fadiga do material. $O$ objetivo desse trabalho é reduzir o desgaste dos insertos no processo de fresamento de titânio e analisar as tensões residuais na usinagem da liga Ti6Al4V, material amplamente utilizado em automóveis e aviões, porém de reconhecida baixa usinabilidade.

\section{MATERIAIS E MÉTODOS}

\subsection{Medições de Tensões Residuais por Difração de Luz Síncrotron}

Para medição das tensões residuais decorrentes do processo de usinagem nas diferentes estratégias de entrada será adotada a seguinte metodologia:

1. Usinagem das amostras

2. Cálculo das tensões residuais

\subsubsection{Usinagem das amostras}

Para preparação das amostras foi utilizada uma chapa laminada de titânio Ti6Al4V (Gr 5) de $80 \times 240 \times 8 \mathrm{~mm}$. Nesta chapa foram executadas todas as entradas a serem analisadas, conforme ilustrado na figura 5. Foram executadas 6 estratégias de entrada: entrada frontal reta, frontal com redução de avanço, frontal por rolagem, mergulho em rampa, mergulho reto e mergulho helicoidal conforme ilustrado nas figuras 1, 2, 3 e 4. 


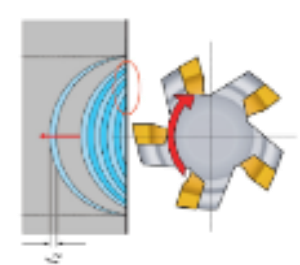

Figura 1 -

Entrada frontal reta

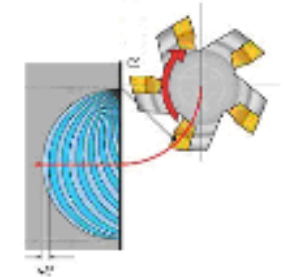

Figura 2 -

Entrada por rolagem

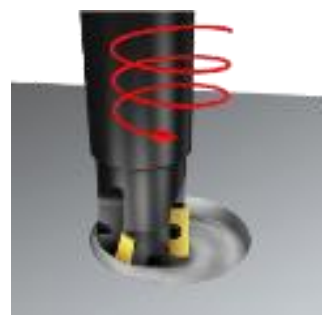

Figura 3 - Mergulho em rampa/helicoidal

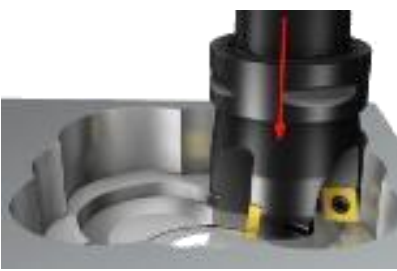

Figura 4 - Mergulho reto

Foi utilizada uma fresa de diâmetro $25 \mathrm{~mm}$, com três insertos redondos de diâmetro $10 \mathrm{~mm}$, conforme figura. Foi utilizado o mesmo tipo de inserto e os mesmos parâmetros de usinagem aplicados nos ensaios de desgaste.

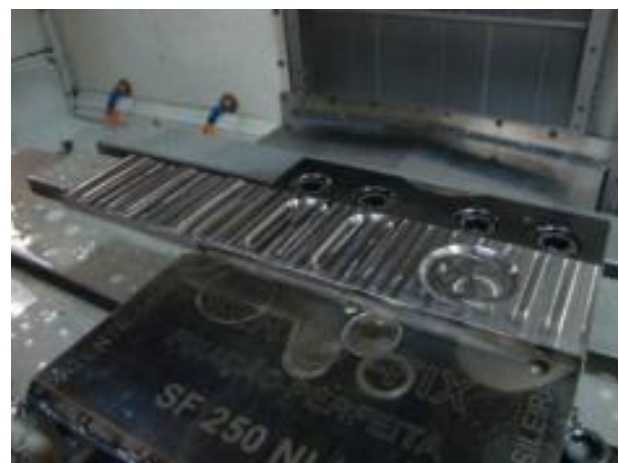

Figura 5 - Chapa de Ti6Al4V usinada

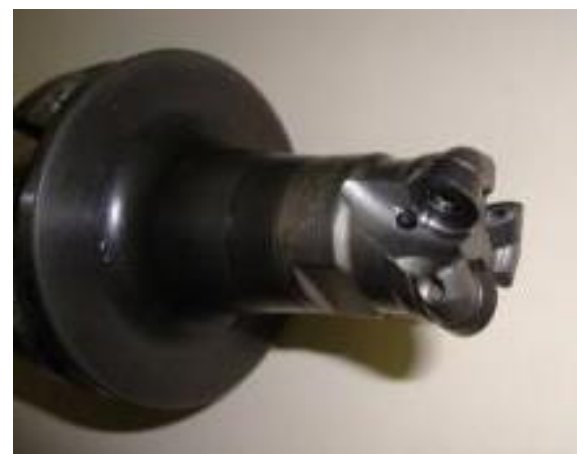

Figura 6 - Detalhe da fresa utilizada na usinagem das amostras

As amostras foram então cortadas com uma fresa de topo inteiriça de diâmetro $5 \mathrm{~mm}$ em peças de diâmetro $25 \mathrm{~mm}$, de forma que pudessem ser posicionadas no portaamostra do difratômetro da linha XRD2 do Laboratório Nacional de Luz Síncrotron (LNLS), conforme mostra a figuras 7 e 8.

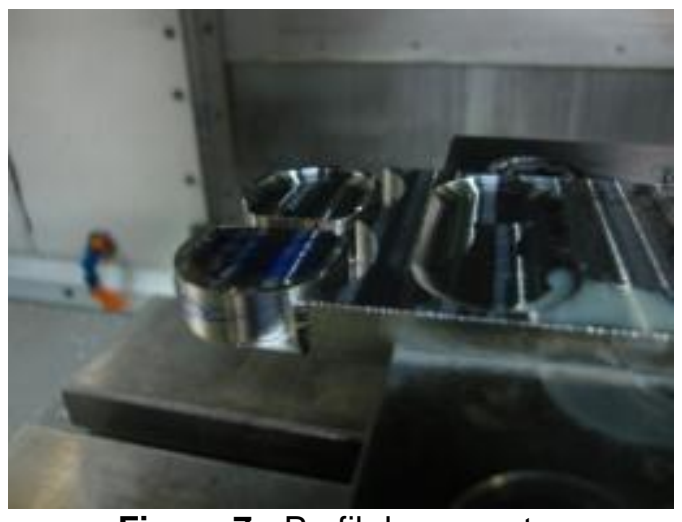

Figura 7 - Perfil das amostras

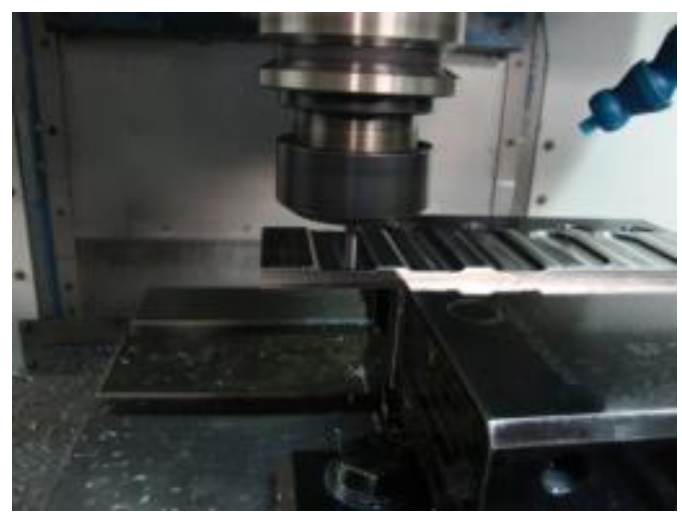

Figura 8 - Fresa de topo inteiriça utilizada para corte das amostras

As amostras foram então numeradas conforme a sequência da posição na chapa, sendo ímpares para a região de entrada da ferramenta e pares para a região de saída da ferramenta. A tabela 1 relaciona o número da amostra com a estratégia de entrada. 
Onde:

$$
\text { n. } \lambda=2 . d \cdot \operatorname{sen}(\theta)
$$

$\mathrm{d}=$ Distância interplanar

$\theta=$ Ângulo de entrada do feixe

e. Coluna E: valor do $\sin ^{2} \psi$.

$2^{\circ}$. Elaboração do gráfico $\sin ^{2} \psi$ vs. d. São esperadas duas retas, sendo uma para $\phi=0^{\circ}$ e outra para $\phi=90^{\circ}$. Será usado o gráfico de dispersão XY do Microsoft Excel.

$3^{\circ}$. Levantamento da equação de reta do gráfico $\sin ^{2} \psi$ vs. d.

$4^{\circ}$. Levantamento do coeficiente angular de cada reta $\left(m_{\varphi=0^{\circ}}\right.$ e $\left.m_{\varphi=90^{\circ}}\right)$, a ser realizado através de uma regressão linear, com a ferramenta Linha de Tendência do Microsoft Excel. Caso o coeficiente angular seja negativo, a tensão residual encontrada será de compressão. Caso positivo, de tração.

5․ Cálculo das tensões para cada direção azimutal $\Phi, \sigma_{\phi=0}$ e $\sigma_{\phi=90^{\circ}}$, com base na equação 3 , sabendo que $\mathrm{d}_{0}=1,7178 \AA$, $\mathrm{E}=113,8 \mathrm{GPa}$ e $v=0,342$.

Onde:

$$
\frac{d_{\phi \psi}-d_{0}}{d_{0}}=\frac{1+v}{E} \sigma_{\phi} \sin ^{2} \psi-\frac{v}{E}\left(\sigma_{11}+\sigma_{22}\right)
$$

$d_{\phi \psi}=$ Distância interplanar medida no material ensaiado

$d_{0}=$ Distância interplanar no material livre de tensão

$v=$ Coeficiente de Poisson

$E=$ Módulo de elasticidade do material

$\psi=$ Ângulo de rotação do anel do difratômetro

$\sigma_{11}=$ Tensão na direção 11

$\sigma_{22}=$ Tensão na direção 22

6․ Cálculo do módulo da tensão residual com a equação 2. Podemos admitir que a tensão residual encontrada na superfície da amostra pode ser expressa pelo módulo das tensões $\sigma_{\phi=0}$ e $\sigma_{\phi=90}$ porque a direção em que a tensão ocorre não é representativa para este estudo.

Onde:

$$
\sigma=\left(\sqrt{\left(\sigma_{\phi=0^{\circ}}\right)^{2}+\left(\sigma_{\phi=90^{\circ}}\right)^{2}}\right)
$$

$\sigma_{\phi}=$ Componente de tensão ao longo do respectivo eixo

\subsection{Medição do Desgaste de Ferramenta}

\subsubsection{Ferramentas utilizadas}

Foram realizados dois experimentos para medição de desgaste da ferramenta, sendo o primeiro com fresa intercambiável de diâmetro $50 \mathrm{~mm}$ e seis insertos de diâmetro $10 \mathrm{~mm}$ cada. As ferramentas foram fornecidas pela empresa Seco Tools, sendo a fresa código R220.29-0050-05.6A e insertos código RDHT10T3M0T-M07 MS2500. O segundo experimento foi realizado com fresa intercambiável de diâmetro $25 \mathrm{~mm}$, código R217.29-1225.RE-05.3A com três insertos, também fornecidos pela empresa Seco Tools.

\subsubsection{Máquina-ferramenta utilizada}




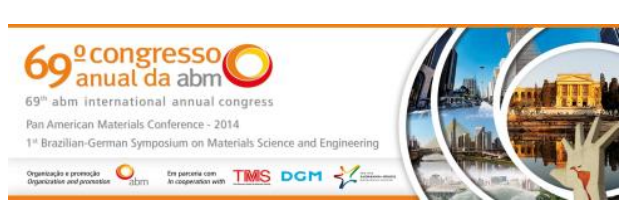

O ensaio de desgaste de ferramenta foi realizado em um centro de usinagem Romi modelo D800 Standard, com cone ISO 40, faixa de rotação de 7 a 7500 RPM, curso máximo em $X, Y$ e $Z$ de 800,530 e $580 \mathrm{~mm}$ respectivamente e mesa de $914 \mathrm{x}$ $500 \mathrm{~mm}$. A potência máxima do motor principal é de $15 \mathrm{~kW}$, com rotação acima de 1607 RPM e o torque máximo é 87 N.m até 1607 RPM. O comando instalado na máquina é o GE Fanuc 0i-MC.

\subsubsection{Trajetórias e parâmetros}

Os ensaios foram realizados durante a produção de uma peça aplicada na indústria aeronáutica (Embraer), fabricada na liga Ti6Al4V, de dimensões aproximadas de $560 \times 430 \times 38 \mathrm{~mm}$, na empresa Finetornos. As trajetórias foram geradas em software CAD-CAM Vero Visi - Machining, sobre modelo matemático da peça. Foram feitas réplicas dos ensaios, permitindo assim análise do desvio padrão do desgaste das ferramentas. Foi gerada trajetória de faceamento para fresa de diâmetro $50 \mathrm{~mm}$, com uma parada intermediária para rotação dos insertos, resultando na remoção total de material de $924 \mathrm{~cm}^{3}$, comprimento total usinado de $19812 \mathrm{~mm}$ e o tempo total 38 minutos para cada amostra. Foram realizados cinco passes com a mesma trajetória, variando a profundidade em $1,5 \mathrm{~mm}$ a cada passe $\mathrm{e}$ totalizando 67 entradas no material. Adotou-se largura de corte (ae) de $40 \mathrm{~mm}$, porém a geometria complexa do material não permitiu que esse parâmetro se fixasse durante toda a trajetória. Foram registradas duas imagens do estado da aresta de corte ao final de cada passe. Após o segundo passe os insertos foram girados para que uma nova aresta fosse testada. Duas peças foram usinadas utilizando-se apenas entradas frontais retas (peças 1 e 4) e mais duas peças com entradas por rolagem (peças 2 e 3). Na figura 13 está a ilustração da trajetória de faceamento da peça.

Para a fresa de diâmetro $25 \mathrm{~mm}$ foi programada uma trajetória de desbaste de três cavidades na peça, com uma parada intermediária para rotação dos insertos. A remoção total de material foi de $568 \mathrm{~cm}^{3}$, o comprimento total usinado foi $22480 \mathrm{~mm}$ e o tempo total 43 minutos para cada amostra. Foram realizados dez passes com a mesma trajetória variando a profundidade em $1,5 \mathrm{~mm}$ a cada passe, totalizando 10 mergulhos da ferramenta em cada peça. Adotou-se largura de corte (ae) de $15 \mathrm{~mm}$, porém a geometria complexa da peça não permitiu que esse parâmetro se fixasse durante toda a trajetória. Foram registradas duas imagens do estado da aresta de corte ao final de cada passe. Após o quinto passe os insertos foram girados para que uma nova aresta fosse testada. Foram usinadas duas peças utilizando a estratégia de rampa com $15^{\circ}$ sem redução no avanço e mais duas peças com a estratégia de entrada por mergulho frontal e avanço reduzido para $150 \mathrm{~mm} / \mathrm{min}$. Na usinagem da primeira peça ocorreram falhas catastróficas e perda da aresta de corte, assim foi necessário reprogramar a última peça para que se usinassem cinco passes de cada estratégia e se mantivesse a proporção de réplicas. A ilustração da geometria das cavidades fresadas pode ser visualizada na figura 14 . 

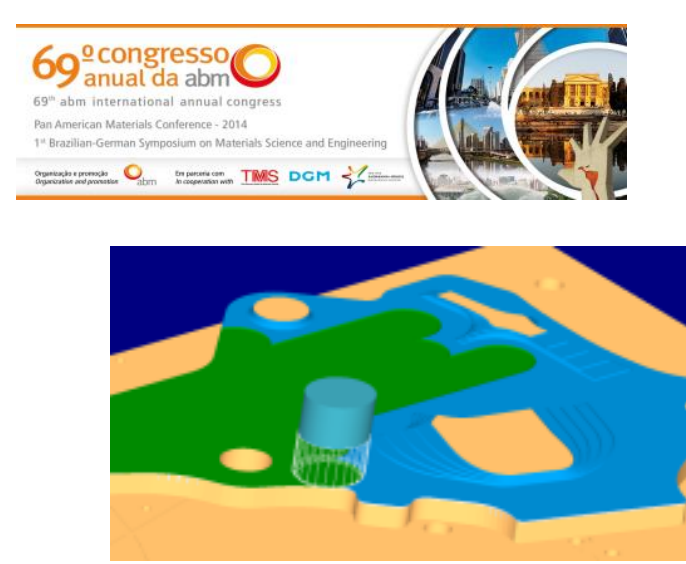

Figura 13 - Modelamento do faceamento da peça

Durante toda a usinagem foi empregado o fluido de base vegetal Castrol Carecut $S$ 142 BF em abundância sobre a região de corte. Foram adotados os parâmetros de usinagem indicados na tabela 3 .

Tabela 3 - Parâmetros de usinagem

\begin{tabular}{|r|c|c|}
\hline \multicolumn{1}{|c|}{ Parâmetros } & Fresa diâmetro $25 \mathrm{~mm}$ & Fresa diâmetro 50mm \\
\hline Velocidade de corte $(\mathrm{Vc})$ & $80 \mathrm{~m} / \mathrm{min}$ & $80 \mathrm{~m} / \mathrm{min}$ \\
\hline Avanço por faca $(\mathrm{fz})$ & $0,17 \mathrm{~mm}(3 \mathrm{facas})$ & $0,17 \mathrm{~mm}(6$ facas $)$ \\
\hline Profundidade de corte $(\mathrm{ap})$ & $1,50 \mathrm{~mm}$ & $1,50 \mathrm{~mm}$ \\
\hline Rotação & $1020 \mathrm{RPM}$ & $510 \mathrm{RPM}$ \\
\hline Avanço de mesa & $520 \mathrm{~mm} / \mathrm{min}$ & $520 \mathrm{~mm} / \mathrm{min}$ \\
\hline Potência de corte & $0,55 \mathrm{~kW}$ & $1,4 \mathrm{~kW}$ \\
\hline
\end{tabular}

\subsubsection{Método de medição do desgaste}

O acompanhamento do desgaste dos insertos foi realizado fotografando o estado da aresta de corte a cada passe de usinagem. Em cada fotografia foi registrado 0 tempo de usinagem, permitindo o acompanhamento da evolução do desgaste. Foi utilizada uma câmera fotográfica Sony Cyber-shot modelo DSC-W 220, com zoom óptico de $4 x$, lente grande angular de $30 \mathrm{~mm}$ e resolução de 12,1 mega pixels. Foi utilizado um tripé como acessório para evitar vibração da câmera durante a captura das imagens. Elas foram feitas sempre do mesmo inserto no suporte, para eliminar o erro causado por possíveis variações no desgaste entre eles. Após a coleta das imagens, foi feita a contagem de pixels da altura do entalhe e da espessura do inserto, utilizando o software Paint. Como a espessura do inserto é conhecida (3,97mm), é possível estabelecer a razão entre as contagens de pixels e determinar o desgaste, como ilustrado nas figuras 15 e 16. 


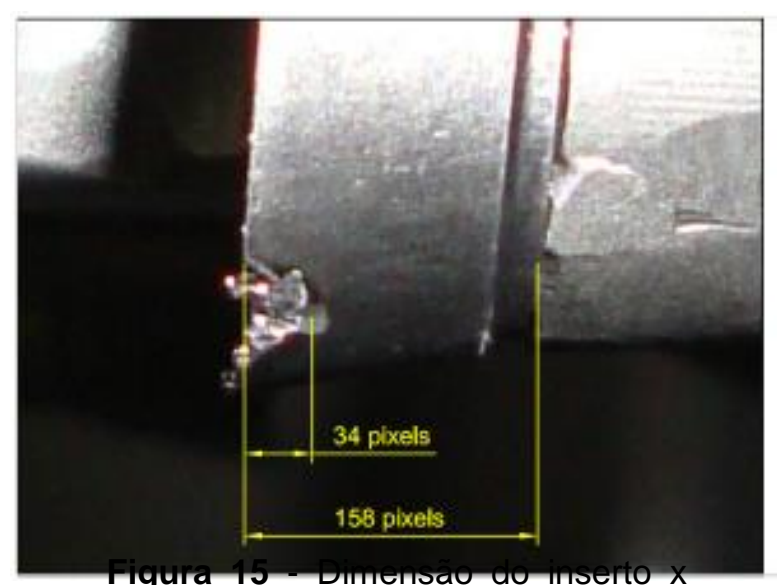

desgaste por pixels

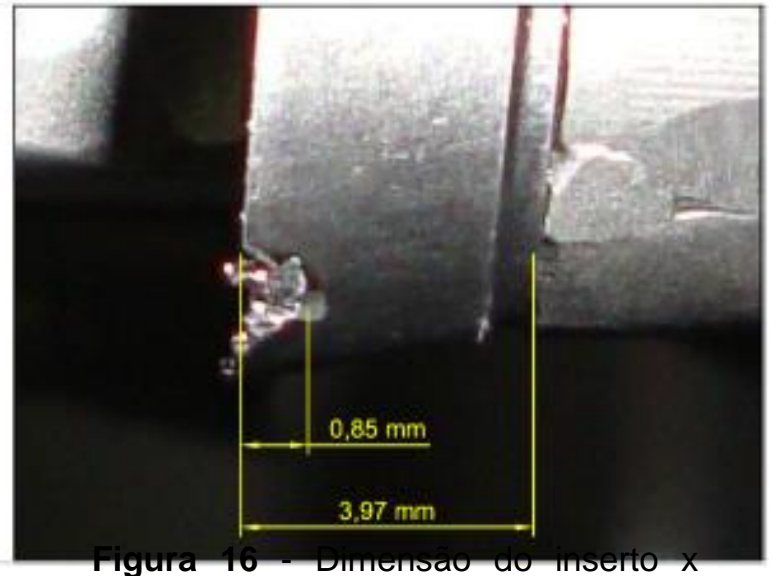

desgaste em $\mathrm{mm}$

\section{RESULTADOS E DISCUSSÃO}

\subsection{Medições de Tensões Residuais por Difração de Luz Síncrotron}

A figura 17 representa os dados coletados no difratômetro para a amostra 1, que resultou em tensão residual $\sigma_{1}=-564 \mathrm{MPa}$.

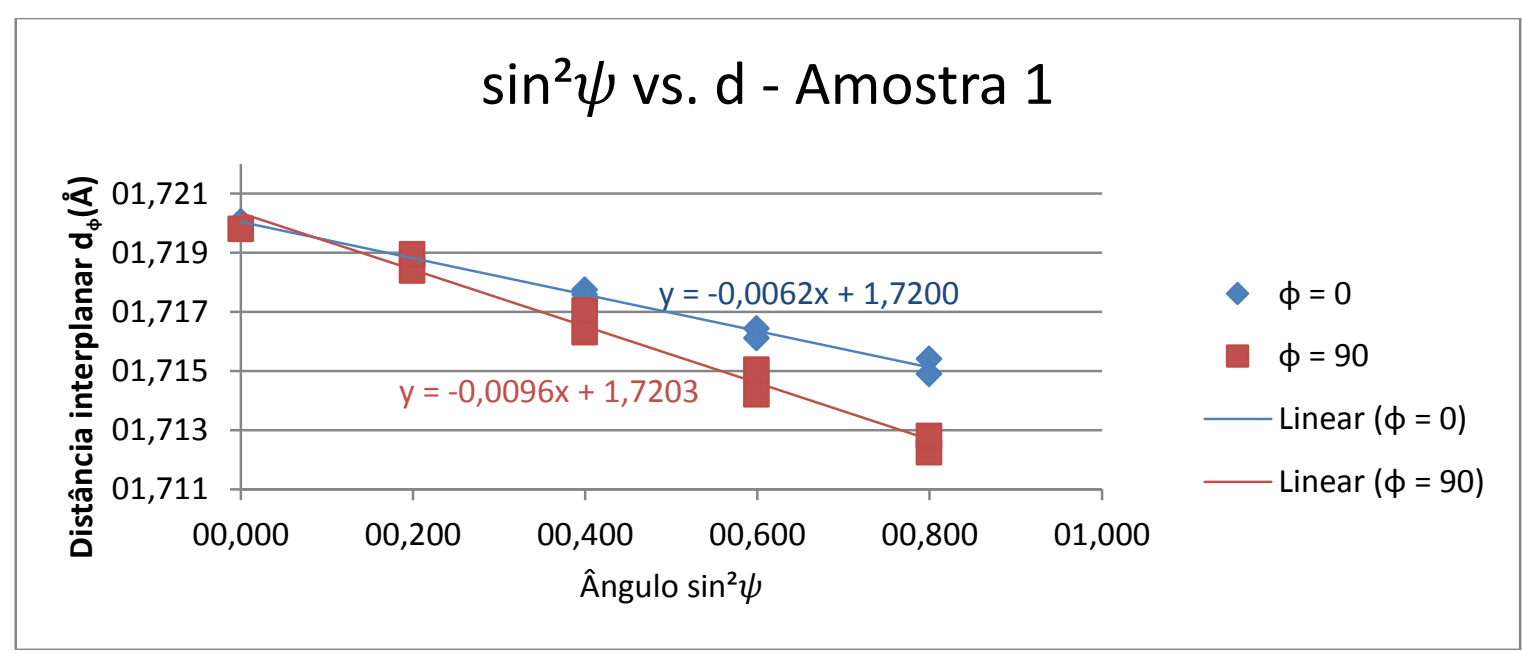

Figura 17 - Gráfico $\sin ^{2} \psi$ vs. d da amostra 1

A figura 18 representa os dados coletados no difratômetro para a amostra 5, que resultou em tensão residual $\sigma_{5}=-517 \mathrm{Mpa}$. 


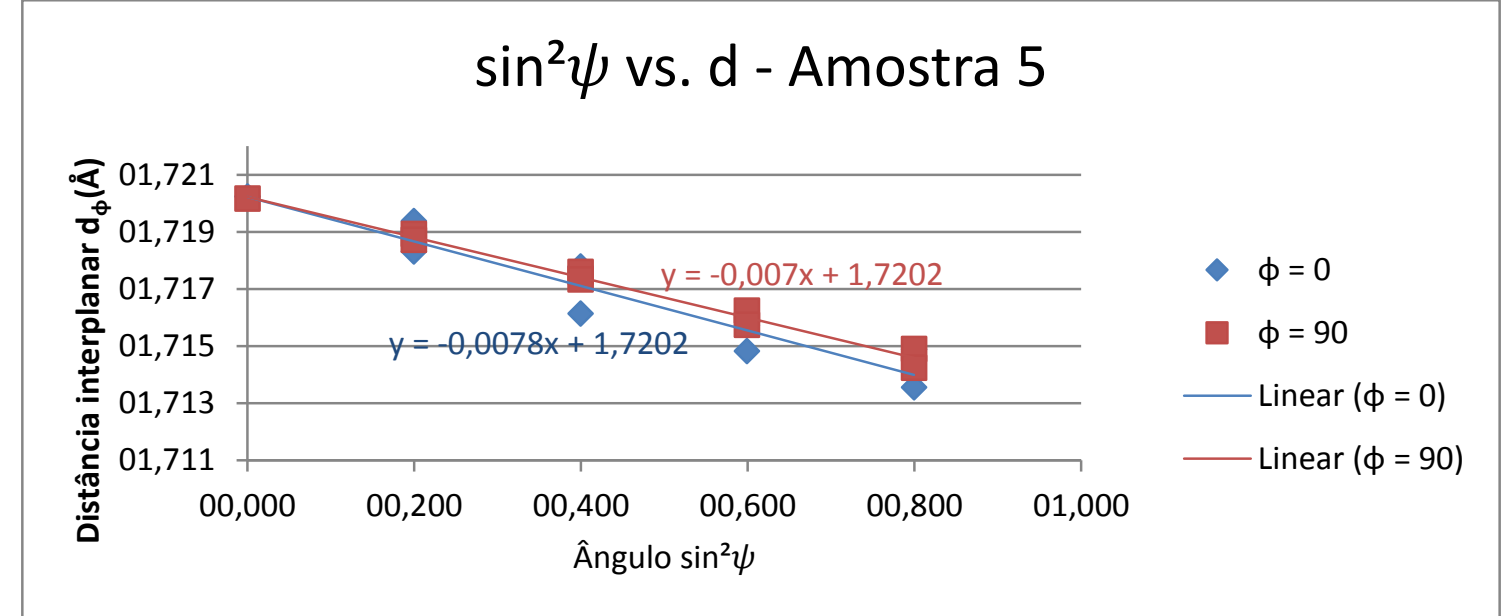

Figura 18 - Gráfico $\sin ^{2} \psi$ vs. $d$ da amostra 5

A figura 19 representa os dados coletados no difratômetro para a amostra 7, que resultou em tensão residual $\sigma_{7}=-378 \mathrm{Mpa}$

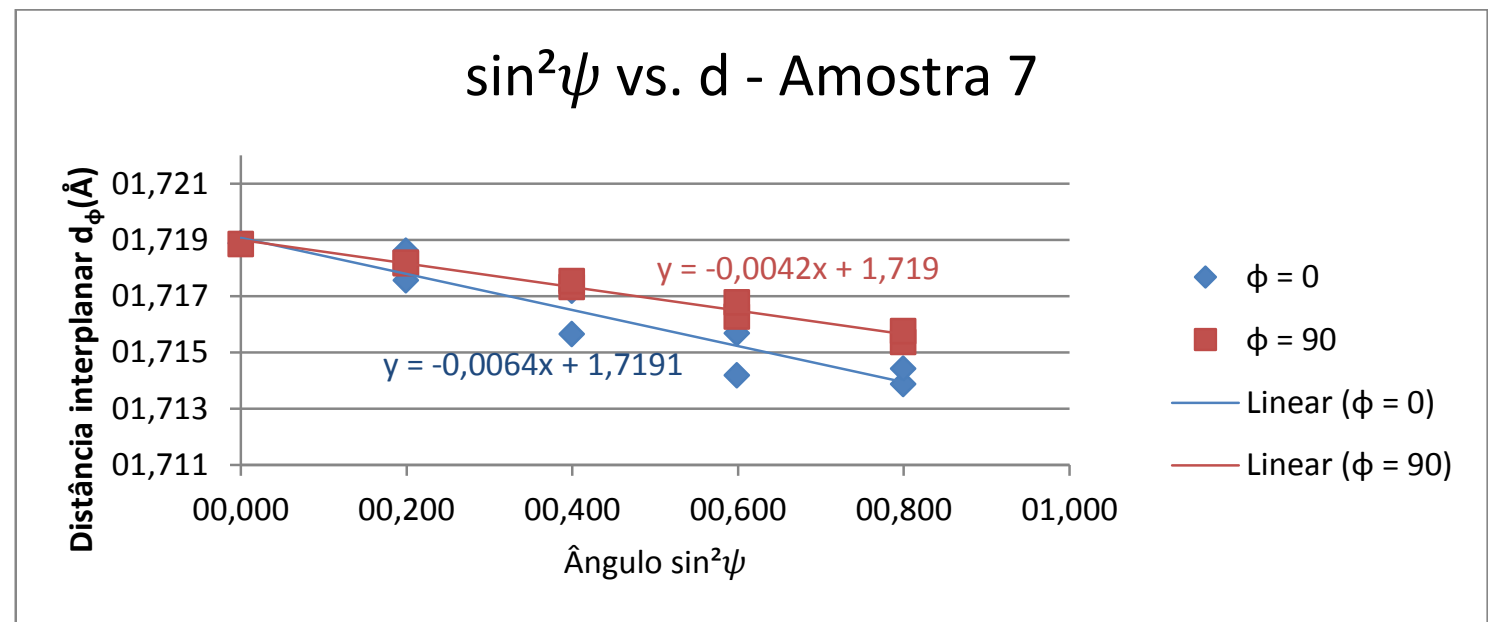

Figura 19 - Gráfico $\sin ^{2} \psi$ vs. d da amostra 7

A figura 20 representa os dados coletados no difratômetro para a amostra 11, que resultou em tensão residual $\sigma_{11}=-755 \mathrm{MPa}$.

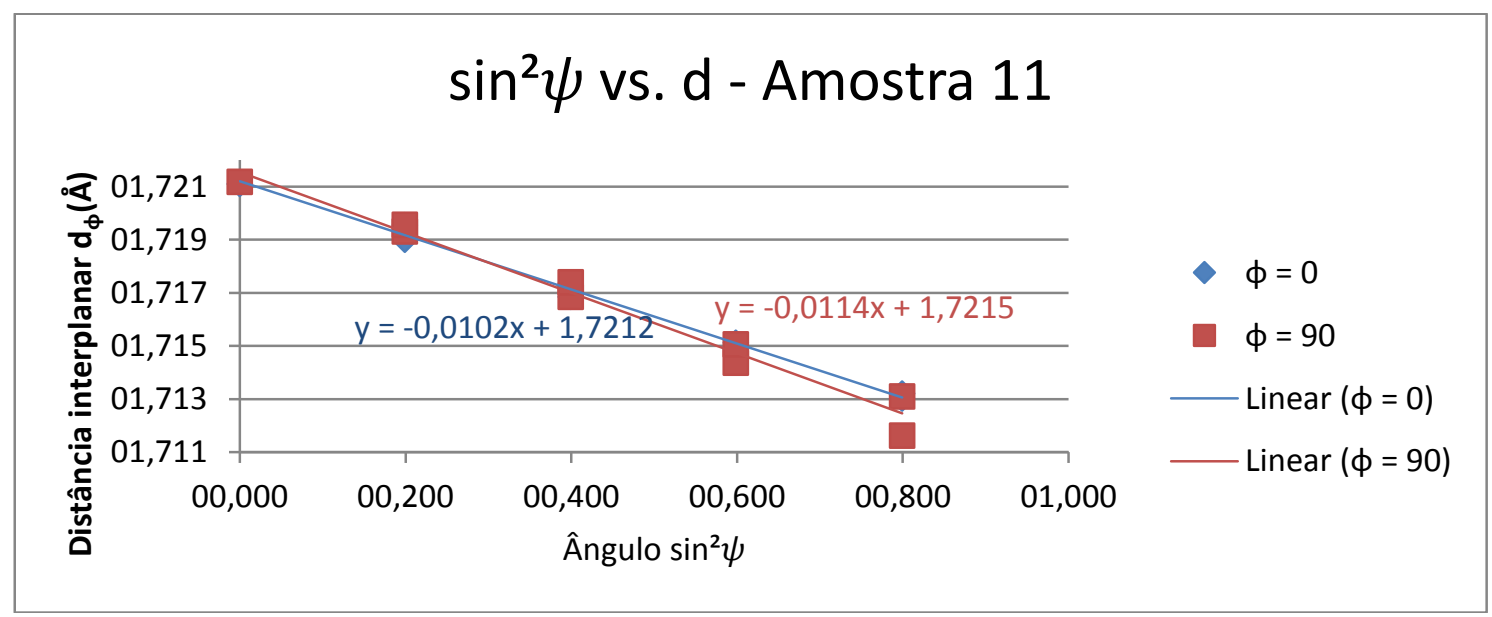

Figura 20 - Gráfico $\sin ^{2} \psi$ vs. d da amostra 11 


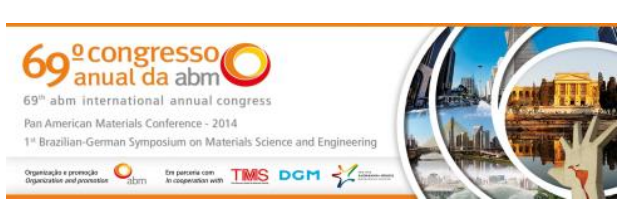

A verificação da posição do pico de difração do pó recozido foi feito com ajuste de Lorentz ao invés do ajuste de Area Pseudo-Voigt. Este último é muito útil em picos simétricos, mas é falho quando o pico é assimétrico. Os picos de difração obtidos com o pó recozido apresentaram comportamento assimétrico, com cauda para esquerda. Este comportamento ocorreu devido à resolução utilizada na coleta dos dados e ao fato do pico ser muito fino. O pico foi projetado por apenas três pontos. $\mathrm{Na}$ figura 21 pode-se observar que o último ponto diverge dos demais. Isto ocorre devido à baixa qualidade do pico observado com $\psi$ de $63,4^{\circ}$ (Figura ).

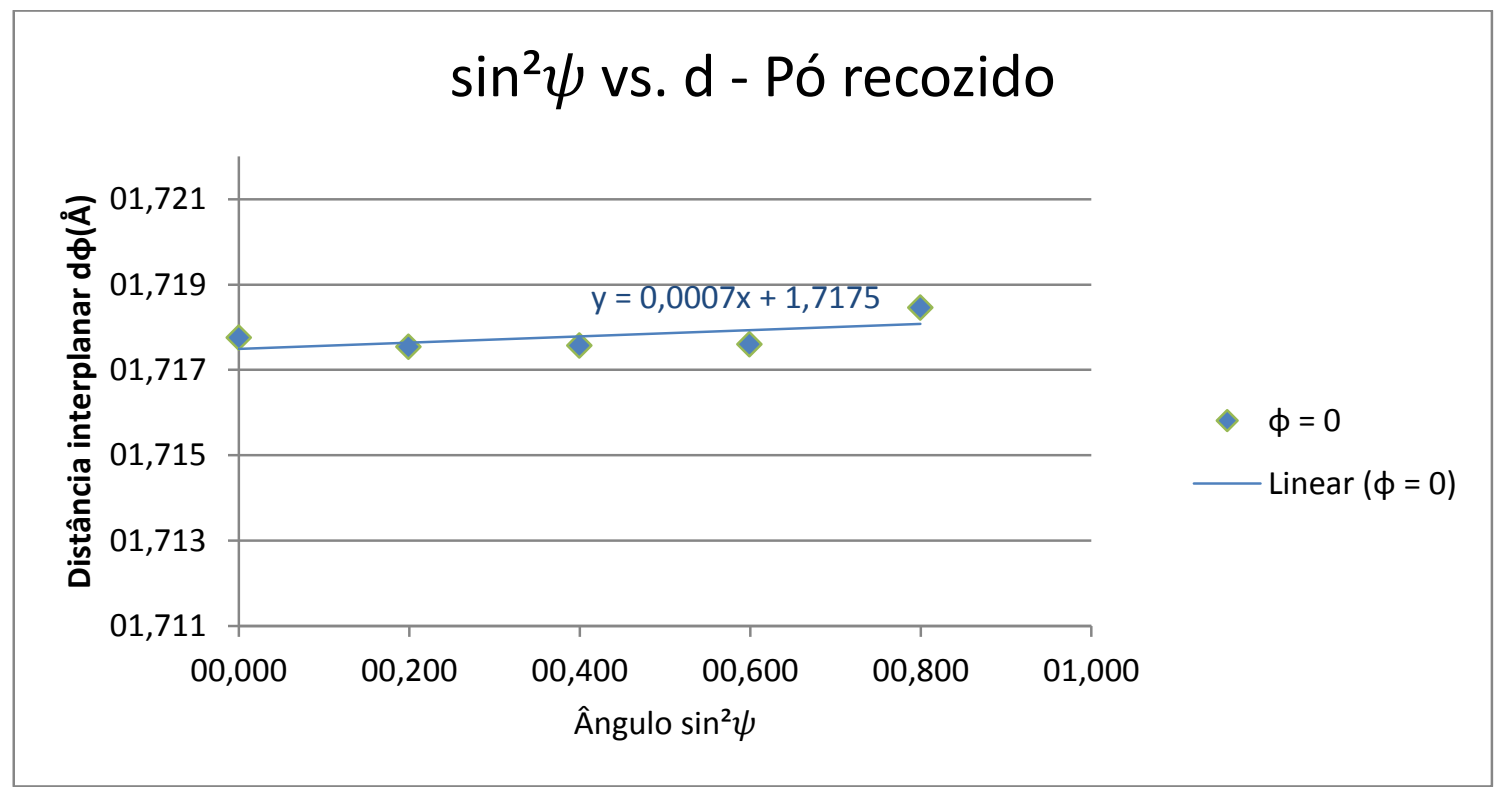

Figura 21 - Gráfico $\sin ^{2} \psi$ vs. d do pó recozido

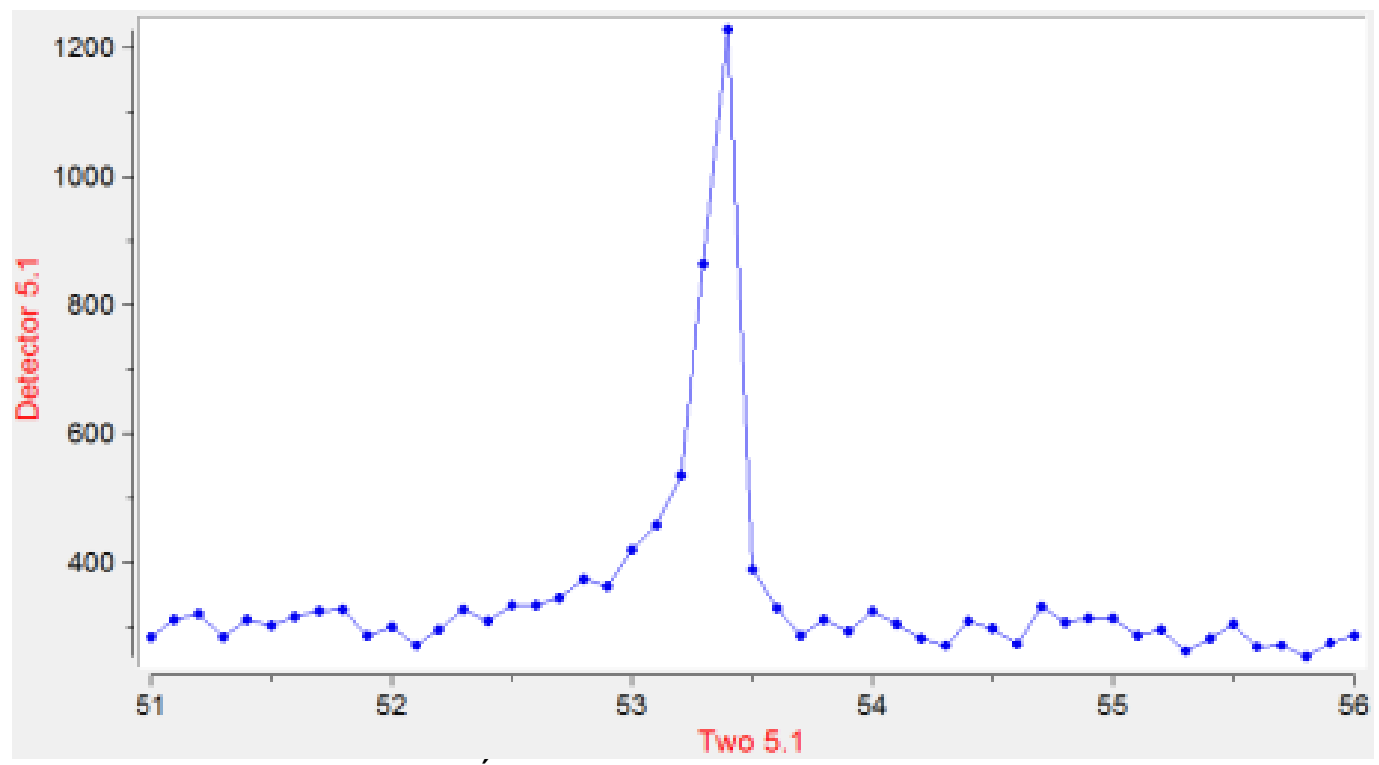

Figura 22 - Última coleta de pontos do pó recozido

Por esta razão optou-se por desconsiderar o ponto em questão, conforme ilustração da figura 23: 

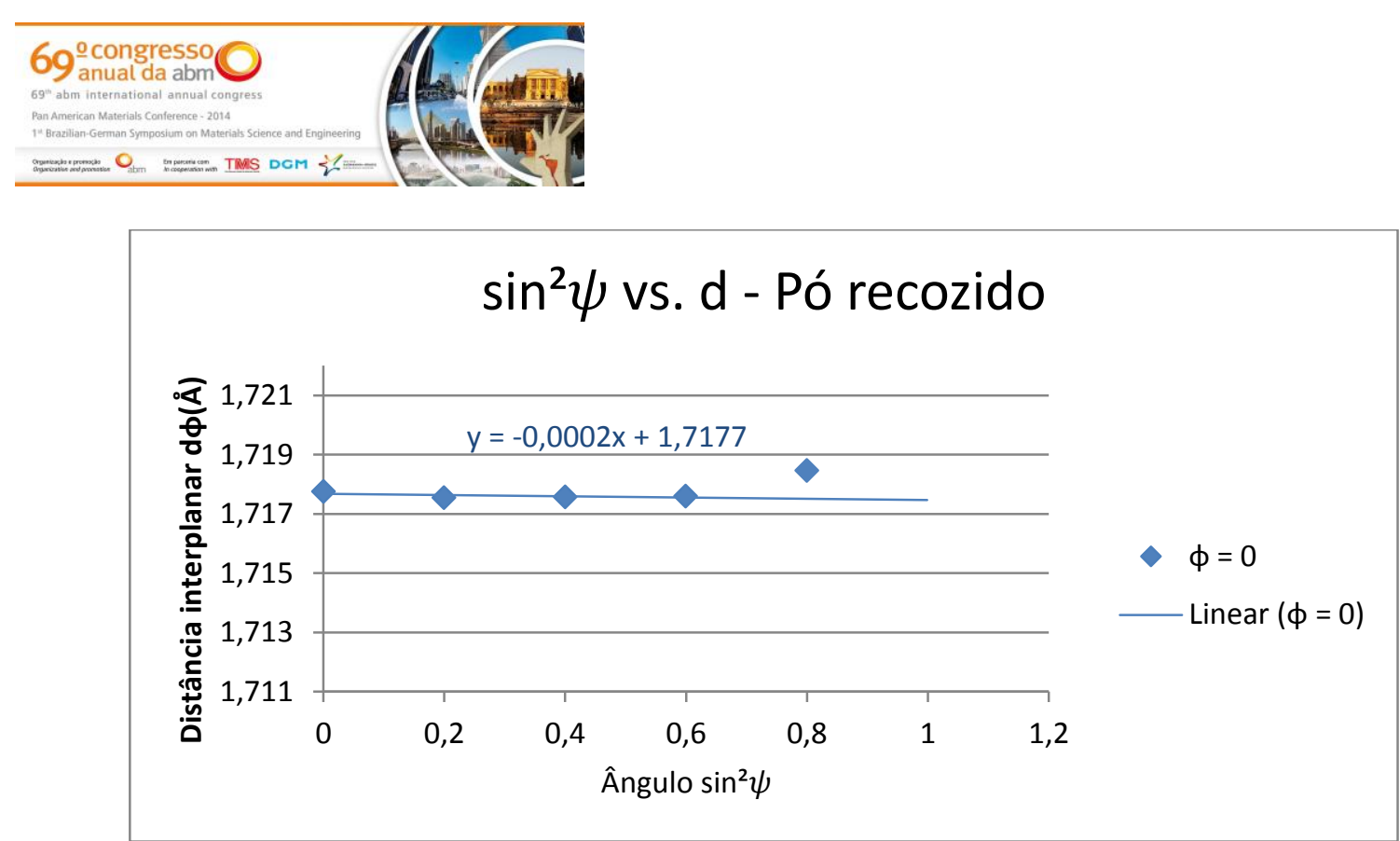

Figura 23 - Gráfico $\sin ^{2} \psi$ vs. d do pó recozido, desprezando $\sin ^{2} \psi=0,8$

Tensão residual $\sigma_{\phi=0}=-10 \mathrm{MPa}$

O valor do parâmetro de rede medido no pó recozido foi $1,7177 \AA ̊$.

A tensão residual de compressão de $10 \mathrm{MPa}$ observada no pó recozido representa que há um erro sistemático da ordem de $10 \mathrm{MPa}$ no processo de medição utilizado. Tal erro pode ser tolerado, pois a menor tensão medida é da ordem de $370 \mathrm{MPa}$, ou seja, há um desvio de $2,7 \%$ na medição, não justificando que sejam feitas correções nos valores calculados anteriormente.

Resumindo os dados, é possível estabelecer a seguinte relação entre a estratégia de entrada e o módulo da tensão residual ilustrado na figura 24:

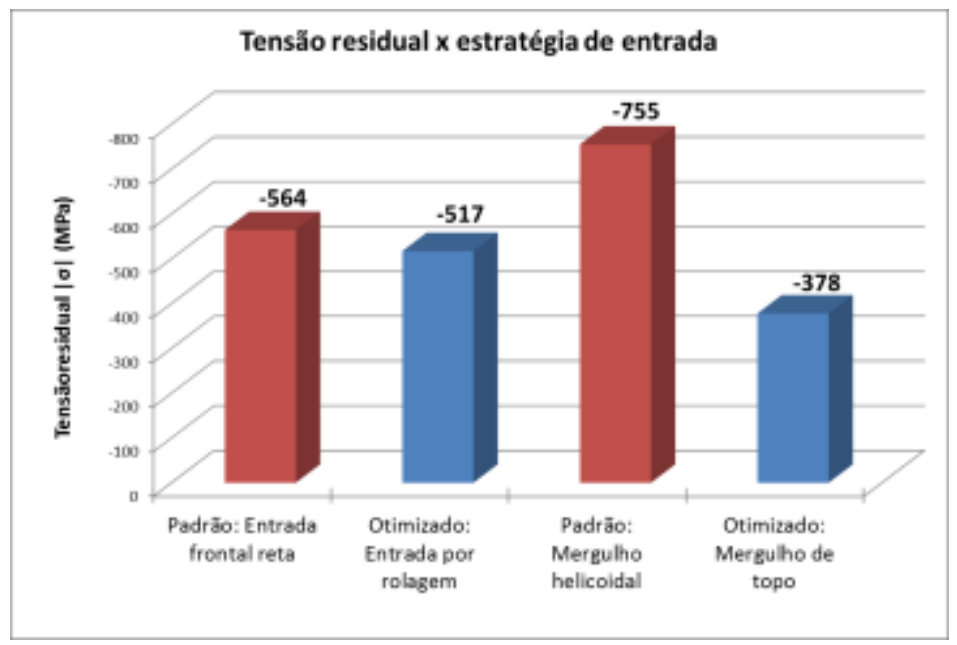

Figura 24 - Comparativo das tensões residuais

Os valores de tensão em todas as estratégias foram de ordem compressiva conforme o esperado. Como relacionado nas referências bibliográficas, as tensões de compressão são benéficas para a vida em fadiga da peça. Nas estratégias de entrada frontal os valores de tensão residual foram semelhantes com variação de $8 \%$ e nas estratégias de mergulho os valores de tensão residual apresentaram variação significativa. A estratégia de mergulho helicoidal resultou em maior valor de tensão se comparado com as demais. 


\subsection{Medição de Desgaste de Ferramenta}

$\mathrm{Na}$ figura 25 pode-se observar a evolução do entalhe causado pelo desgaste do inserto no faceamento da liga de titânio.
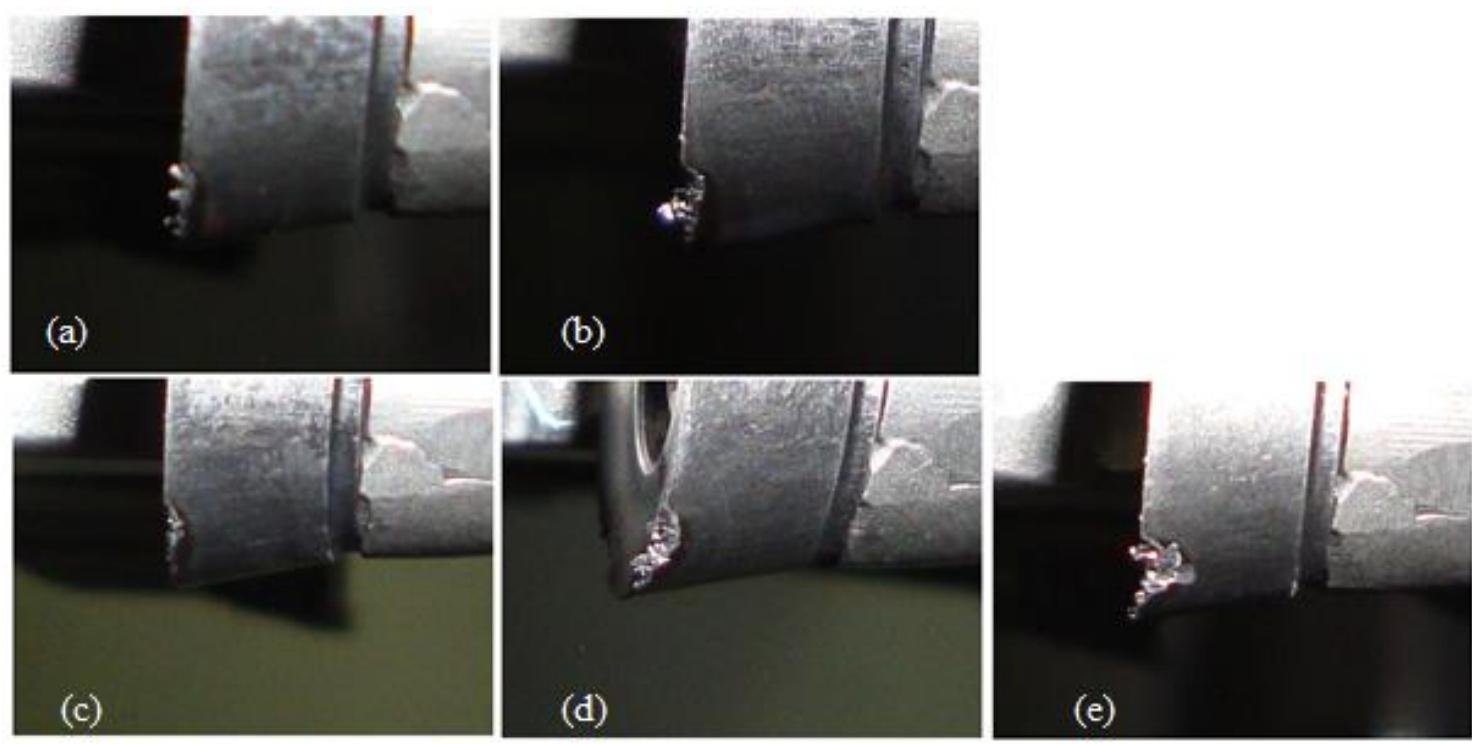

Figura 25 - Desgaste Fresa $\varnothing 50$ Peça 1 (a) $1^{\text {a }}$ aresta em 0:08:04; (b) 1ํㅡㄹ aresta em 0:15:49;

(c) $2^{\underline{a}}$ aresta em 0:07:46; (d) $2^{\underline{a}}$ aresta em 0:15:35; (e) $2^{\underline{a}}$ aresta em 0:22:18

O desgaste dos insertos resultante da operação de faceamento pode ser observado na tabela 4, onde estão classificados entre a primeira e segunda aresta de cada peça usinada.

Tabela 4 - Desgaste resultante no faceamento

\begin{tabular}{|c|c|c|c|c|c|}
\hline \multirow{2}{*}{} & & \multicolumn{4}{|c|}{ Desgaste (mm) } \\
\cline { 3 - 6 } & Tempo & Peça 1 & Peça 2 & Peça 3 & Peça 4 \\
\cline { 3 - 6 } & Frontal & Rolagem & Rolagem & Frontal \\
\hline \multirow{2}{*}{$1^{\text {a }}$ aresta } & $0: 08: 04$ & 0,27 & 0,10 & 0,24 & 0,32 \\
\cline { 2 - 6 } & $0: 15: 49$ & 0,41 & 0,16 & 0,33 & 0,38 \\
\hline \multirow{3}{*}{$2^{\text {a }}$ aresta } & $0: 07: 46$ & 0,34 & 0,19 & 0,20 & 0,43 \\
\cline { 2 - 6 } & $0: 15: 35$ & 0,53 & 0,46 & 0,28 & 0,51 \\
\cline { 2 - 6 } & $0: 22: 18$ & 0,85 & 0,57 & 0,61 & 0,84 \\
\hline
\end{tabular}

A evolução do desgaste de flanco é exibida nas figuras 26 e 27, diferenciando as estratégias e evidenciando o desvio padrão observado no fresamento da réplica.

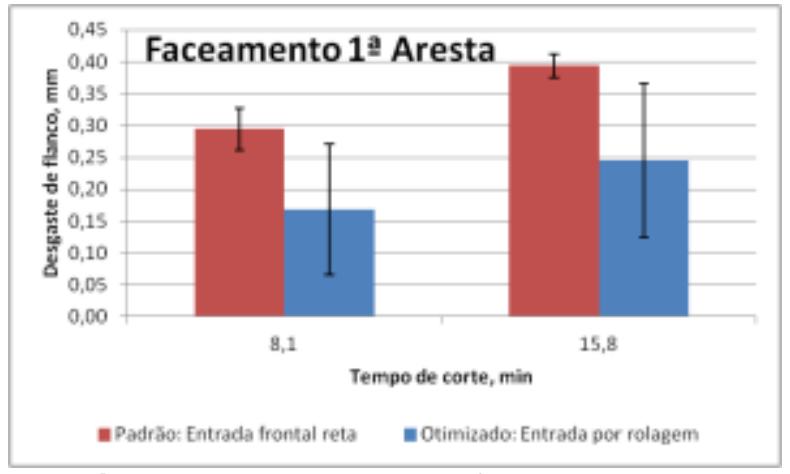

Figura 26 - Desgaste de flanco x Tempo de corte - Faceamento $1^{\underline{a}}$ aresta

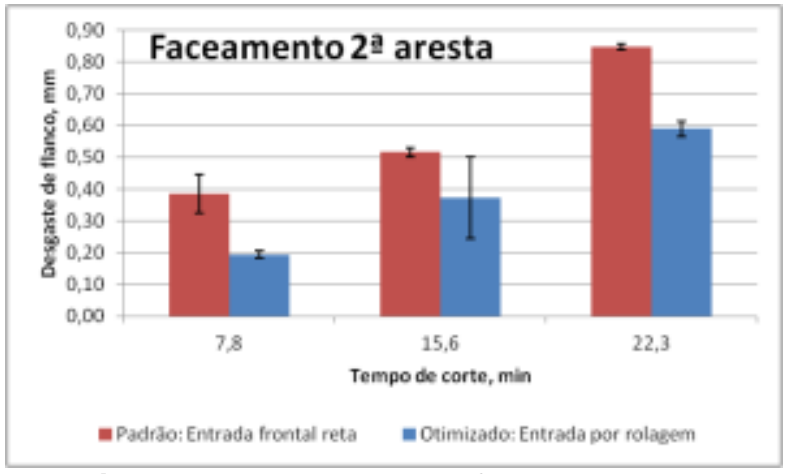

Figura 27 - Desgaste de flanco x Tempo de corte - Faceamento $2^{\mathrm{a}}$ aresta 


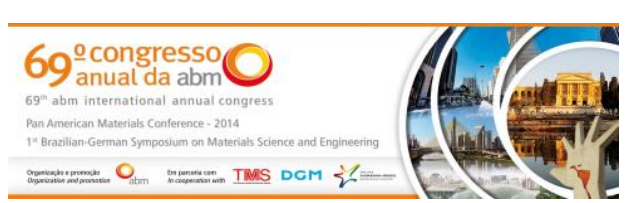

Houve uma sensível redução do desgaste da aresta de corte durante o faceamento com a aplicação da entrada por rolagem, uma vez que a espessura média do cavaco é reduzida e evita os impactos decorrentes da penetração da ferramenta no material. $\mathrm{Na}$ figura 28 pode-se observar a evolução do desgaste de flanco do inserto no faceamento da liga de titânio. $O$ experimento com a peça 1 foi descartado por causa da ocorrência de falha catastrófica durante o ensaio.

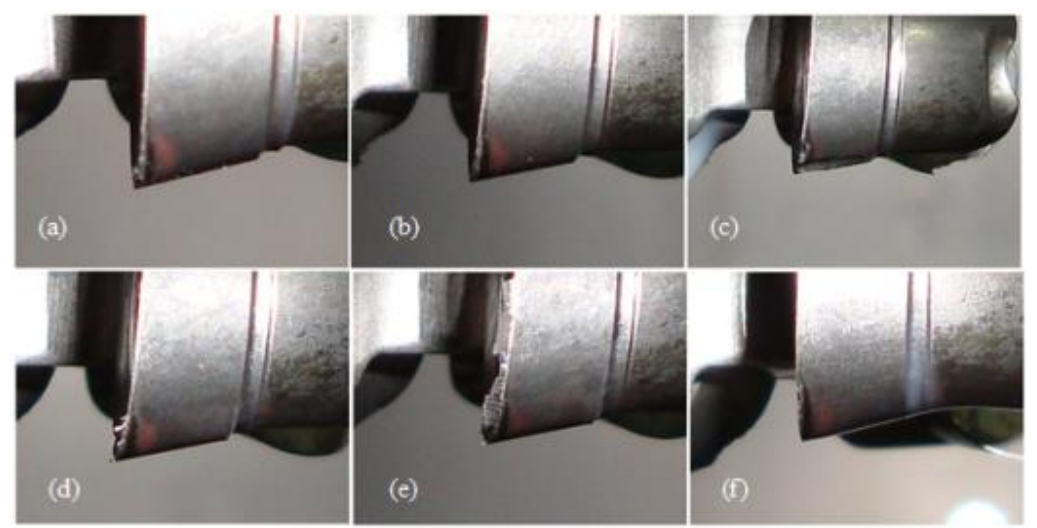

Figura 28 - Desgaste Fresa $\varnothing 25$ Peça 2 (a) $1^{\underline{a}}$ aresta em 0:08:19; (b) $1^{\text {a }}$ aresta em 0:13:37; (c) $1^{\underline{a}}$ aresta em 0:21:44; (d) $2^{\underline{a}}$ aresta em 0:08:19; (e) $2^{\underline{a}}$ aresta em 0:13:37; (e) $2^{\underline{a}}$ aresta em 0:21:44

O desgaste observado no fresamento de cavidades é mostrado na tabela 5 , onde a cor azul representa a estratégia de mergulho de topo e em vermelho o mergulho em rampa.

Tabela 5 - Desgaste no fresamento das cavidades

\begin{tabular}{|c|c|c|c|c|c|}
\hline & \multirow[b]{2}{*}{ Tempo } & \multicolumn{4}{|c|}{ Desgaste (mm) } \\
\hline & & Peça 1 & Peça 2 & Peça 3 & Peça 4 \\
\hline \multirow{3}{*}{$\begin{array}{c}1^{\mathrm{a}} \\
\text { aresta }\end{array}$} & 0:08:19 & 0,74 & 0,10 & 0,22 & 0,16 \\
\hline & $0: 13: 37$ & 0,87 & 0,16 & 0,42 & 0,32 \\
\hline & $0: 21: 44$ & Falha & 0,29 & 0,86 & 0,63 \\
\hline \multirow{3}{*}{$\begin{array}{c}2^{\underline{a}} \\
\text { aresta }\end{array}$} & 0:08:19 & 0,19 & 0,08 & 0,25 & 0,12 \\
\hline & 0:13:37 & Falha & 0,11 & 0,47 & 0,14 \\
\hline & $0: 21: 44$ & Falha & 0,23 & 0,68 & 0,21 \\
\hline
\end{tabular}

A evolução do desgaste médio de flanco nas cavidades é exibida na figura 29, diferenciando as estratégias e evidenciando o desvio padrão observado no fresamento da réplica.

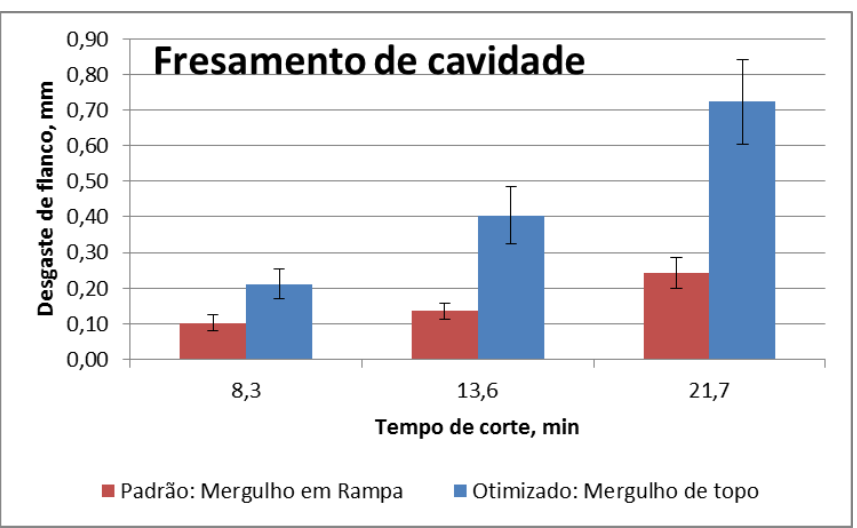

Figura 29 - Desgaste de flanco x Tempo de corte nas cavidades 


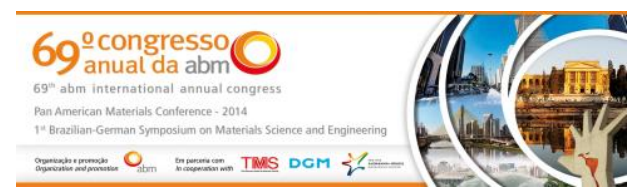

O entalhe causado pelo desgaste do inserto durante o mergulho de topo se mostrou prejudicial quando comparado ao mergulho em rampa, possivelmente pela formação de um cavaco longo, em forma de fita, que aderiu ao suporte de insertos e dificultou tanto o acesso do fluído de corte como o fluxo de cavacos durante a usinagem. Esta condição se repetiu em todas as réplicas em que esta estratégia foi usada.

Analisando os dados obtidos verificou-se que para obter menor desgaste de inserto é recomendado utilizar a estratégia de entrada por rolagem no faceamento ou 0 mergulho em rampa no fresamento de cavidades. É válido observar que ao se utilizar fluido em alta pressão podem-se obter melhores resultados no mergulho reto forçando a saída do cavaco durante a penetração da ferramenta.

\section{CONCLUSÃO}

A pesquisa desenvolvida ao longo deste trabalho buscou reduzir o desgaste dos insertos no processo de fresamento de titânio e analisar as tensões residuais na usinagem da liga Ti6Al4V. No faceamento, a estratégia proposta de entrada por rolagem resultou em um menor desgaste médio de flanco, sendo 0,59 mm após 22,3 min enquanto na estratégia convencional de entrada frontal reta o desgaste médio foi de $0,85 \mathrm{~mm}$ para o mesmo tempo de usinagem. Isso possivelmente ocorreu devido à redução da espessura do cavaco durante a entrada por rolagem da ferramenta no material, reduzindo o efeito dos impactos decorrentes do contato do inserto com a peça e o desgaste em 30\%. Ainda no faceamento, a estratégia proposta resultou em uma tensão residual superficial de $-517 \mathrm{MPa}$, uma pequena redução em relação a estratégia convencional, que resultou $-564 \mathrm{MPa}$. Do ponto de vista de projeto, não há alteração significativa entre as tensões, já que ambas apresentaram-se compressivas. No fresamento de cavidade, a estratégia proposta de mergulho reto resultou em um maior desgaste médio de flanco, sendo 0,72 mm após 21,7 min enquanto na estratégia convencional de mergulho em rampa 0 desgaste médio foi de $0,24 \mathrm{~mm}$ para o mesmo tempo de usinagem. Isso possivelmente ocorreu pela formação de um cavaco longo, em forma de fita, que aderiu ao suporte de insertos e dificultou tanto o acesso do fluído de corte como o fluxo de cavacos durante o mergulho reto. Assim, a estratégia proposta aumentou em $200 \%$ o desgaste do inserto. Ao contrário do observado no faceamento, no fresamento de cavidade houve uma significativa diferença entre as tensões residuais superficiais observadas nas diferentes estratégias, porém ambas também foram compressivas. A proposta de mergulho reto resultou em uma tensão de $-378 \mathrm{MPa}$, uma expressiva redução em relação a estratégia convencional, que resultou em uma tensão de $-755 \mathrm{MPa}$. Os resultados demonstraram que a estratégia de mergulho em rampa promove os melhores resultados quanto ao desgaste de inserto e valores de tensões residuais superficiais.

\section{Agradecimentos}

Agradecemos primeiramente ao Professor Dr. Osmar Roberto Bagnato, nosso orientador, que acreditou em nós e incentivou-nos para a conclusão deste trabalho, face aos inúmeros percalços do trajeto. Agradecemos também ao Professor Dr. Roosevelt Droppa Jr, um companheiro de percurso e de discussões profícuas, dentro e fora do contexto deste trabalho, agraciando-nos incontáveis vezes com sua paciência, conhecimento e amizade. Alguns experimentos e vários "entendimentos"

* Contribuição técnica ao 69 Congresso Anual da ABM - Internacional e ao 14ํㅡNMET - Encontro Nacional de Estudantes de Engenharia Metalúrgica, de Materiais e de Minas, 21 a 25 de julho de 2014, São Paulo, SP, Brasil. 
não teriam sido possíveis sem a colaboração de Cristiane Barbieri Rodella, Douglas Araujo e Enilson Carlos Fim.

\section{REFERÊNCIAS}

1 Antonialli AIS. Uma contribuição ao fresamento frontal da liga de titânio Ti-6AI-4V. Campinas : s.n., 2009.

2 Diniz AE, Marcondes FCE, Coppini NL. Tecnologia da Usinagem dos Materiais. 3. São Paulo : Artliber, 2001.

3 Costa AR. Otimização do Processo de Fresamento de Cavidades com Fresas de Insertos Intercambiáveis, Dissertação de Mestrado, Universidade Estadual de Campinas. 2003.

\section{BIBLIOGRAFIA}

1 Noyan IC, Cohen E, Jerome B. Residual Stress - Measurement by Driffractton and Interpretation. Evanston : Springer-Verlag, 1987.

2 Ferraresi D. Usinagem dos metais: Fundamentos da usinagem dos metais. 1. s.I. : São Paulo, 1970. p. 751.

3 Lu J. Handbook of measurement or residual stresses. Califórnia : Fairmont Press, 1996.

4 Als-Nielsen J, Mcmorrow D. Elements of Modern X-ray Physics. 2ª . Londres : Wiley, 2011. 